Document downloaded from:

http://hdl.handle.net/10251/47586

This paper must be cited as:

Benajes Calvo, JV.; García Martínez, A.; Doménech Llopis, V.; Durret, R. (2013). An investigation of partially premixed compression ignition combustion using gasoline and spark assistance. Applied Thermal Engineering. 52(2):468-477. doi:10.1016/j.applthermaleng.2012.12.025.

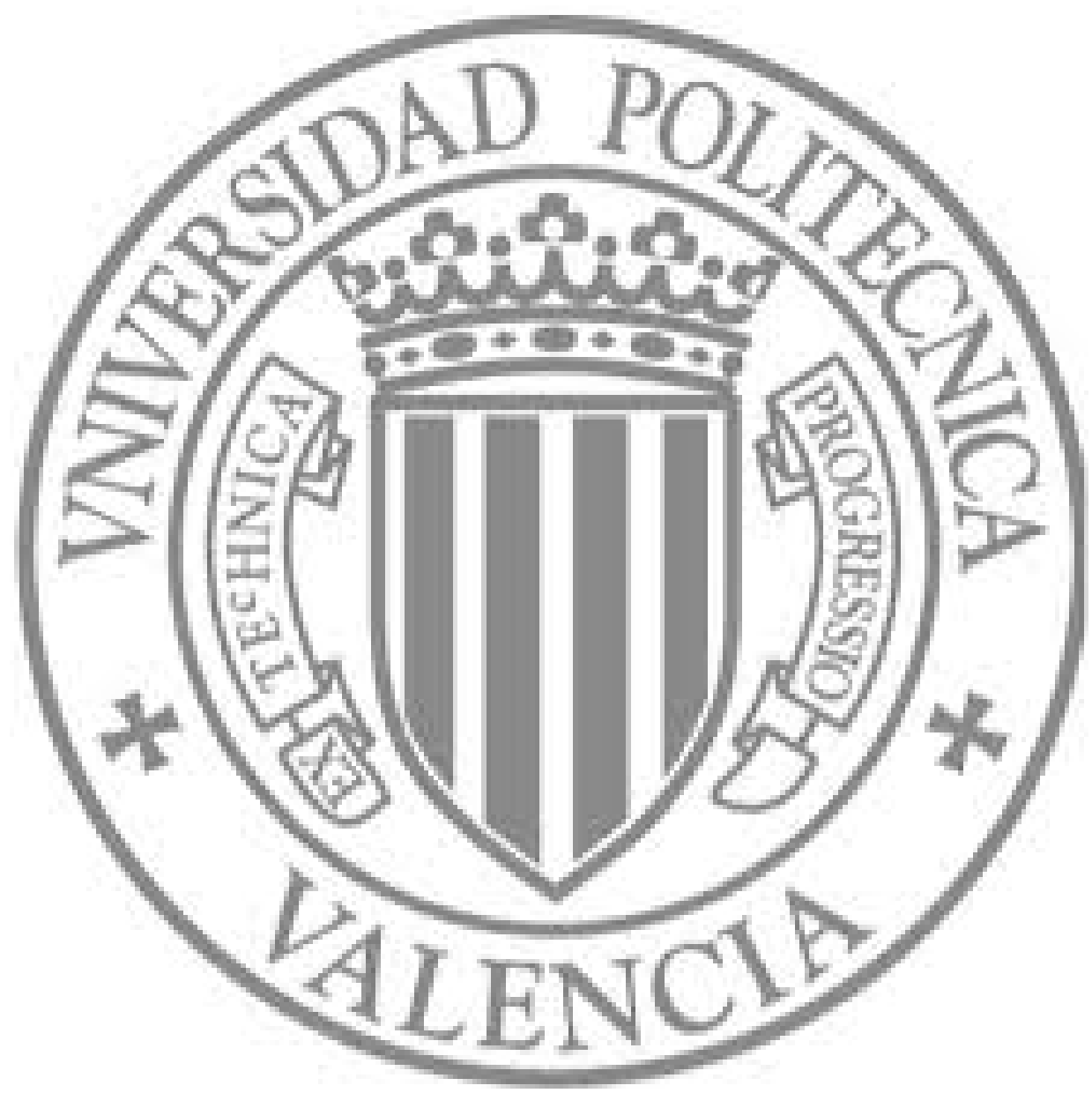

The final publication is available at

http://dx.doi.org/10.1016/j.applthermaleng.2012.12.025

Copyright Elsevier 


\title{
An Investigation of Partially Premixed Compression Ignition Combustion using Gasoline and Spark Assistance
}

\author{
J. Benajes ${ }^{1}$, A. García ${ }^{1}$ and V. Domenech ${ }^{1}$ \\ R. Durrett ${ }^{2}$
}

1: CMT- Motores Térmicos - Universidad Politécnica de Valencia, Camino de Vera s/n 46022 Valencia - SPAIN

2: Diesel Engine Systems Group - Propulsion Systems Research Lab GM R\&D Center, MC: 480-106-252, 30500 Mound Rd, Warren, MI 48090-905

\begin{abstract}
:
Nowadays the automotive scientific community and companies are focusing part of their efforts on the investigation of new combustion modes in $\mathrm{Cl}$ engines, mainly based on the use of locally lean air-fuel mixtures. This characteristic, combined with exhaust gas recirculation, provides low combustion temperatures that reduce pollutant formation. However these combustion concepts have some shortcomings, related to combustion phasing control and combustion stability under the light load engine operating range which must be overcome. The aim of this work is focused on the study of the integration of phasing and cycle-to-cycle repeatability control by means of an ignition spark plug system in a $\mathrm{Cl}$ engine working under partially premixed charge (PPC) in order to overcome the lack of combustion stability in light load conditions when very low fuel reactivity is used. To achieve this objective, experimental tests have been carried out in a single cylinder optical engine combining broadband luminosity images with cylinder pressure derived heat release rate analysis. Research results reveals the spark assistance as a proper methodology to provide temporal and spatial control over the combustion process solving the lack of cycle to cycle control on the highly premixed compression ignition modes overall in light loads with high ON fuels. Additionally, different stages have been identified in the combustion mode. The process starts with the spark discharge, which produces a flame kernel around the spark plug that later evolves to a premixed flame front. This premixed flame front heats unburned mixture and progresses into an auto-ignition combustion that burns out the rest of the charge with higher light intensity and finally an extinction of combustion process. Finally, the effect of injected fuel mass in the combustion mode has been also tested. An increase in the injected fuel mass has a positive effect on the assistance of the spark at the combustion process for both, combustion stability and cycle to cycle control.
\end{abstract}

\section{Keywords: PPC combustion, spark assistance, high ON gasoline}

\section{Introduction}

Nowadays the automotive scientific community and companies are focusing part of their efforts on the investigation of new combustion modes [1] and on the optimization of the current technology with the aim of reducing fuel consumption and emissions in internal combustion engines (ICE) [2], more specifically in $\mathrm{Cl}$ (Compression Ignition) diesel engines [3]. Most of these new combustion concepts are achieved by using different strategies that produce a leaner mixture, using medium and high levels of EGR to provide low temperature combustions with the objective of decoupling the injection and combustion phases. Consequently, high efficiency is achieved along with a decrease in the most relevant $\mathrm{Cl}$ diesel engine emissions, NOx and soot [4]. These combustion concepts based on partially or fully premixed lean mixtures are commonly known as Homogeneous Charge Compression Ignition ( $\mathrm{HCCl}$ ), Premixed Charge Compression Ignition (PCCl), etc. Even though they achieve important emission benefits, these combustion concepts present some practical issues that must be overcome before they can be implemented in $\mathrm{Cl}$ diesel engines and, therefore, are generally confined to low engine speeds and loads. The most relevant PCCI known limitations consist of achieving an appropriate combustion phasing, the cycle-to-cycle control of the combustion process, the noise and operating range extent.

With the aim of overcoming these drawbacks, in the last few years different strategies have been proposed for improving the cycle-to-cycle control and adjusting the combustion phasing and noise in these new combustion modes $[5,7]$. Some of the most relevant strategies and methods are the control of the intake air temperature, the 
modification of the compression ratio, the use of different injection strategies, the EGR rate control [7] or the control of the amount of trapped combustion gases by using variable valve actuation systems. Additionally, all these processes and strategies try to compensate the high chemical reactivity of the diesel fuel that does not provide enough mixing time before the start of combustion to achieve a significant emissions reduction. Thus, recent studies tried to overcome these disadvantages by using fuels with different reactivity. To this regard, PPC (Partially Premixed Combustion) is a newly-developed combustion mode; which main characteristic is its use of low fuel reactivity $[8,9, \mathbf{1 0}$. This combustion mode represents a transition between the conventional diffusioncontrolled combustion in $\mathrm{Cl}$ engines and the Premixed Charge Compression Ignition ( $\mathrm{PCCl}$ ) concept, meaning that fuel and air are mixed before combustion, but the charge is not completely homogeneous [11]. Recently, Sjöberg et al [12] confirmed how partial fuel stratification might be a promising method to control the heat release rate in this combustion mode. Partially Premixed Combustion provides the potential of simultaneous reduction of $\mathrm{NOx}$ and soot for $\mathrm{Cl}$ engines, while fuel consumption and efficiency are improved. Nevertheless, while all these solutions provide some control on combustion phasing still not solve the possibility of cycle-to-cycle control. Moreover, when a very low reactivity fuel is used, such as gasoline with octane number greater than 90 , it is not possible to achieve stable engine operation for light and mid load conditions [22].

Recent investigations $[13,14]$ on gasoline engines $(\mathrm{SI})$ running in homogenous or premixed combustion modes as CAI (always PFI), have shown the potential of using the assistance of a spark plug for achieving cycle-to-cycle control and combustion phasing. In these investigations, combustion with different phases was observed. In the first phase the spark plug was used to supply the necessary energy to ignite the mixture before auto-ignition timing. Thus, the cycle-to-cycle combustion phasing can be controlled by controlling the spark discharge timing [16]. This method is called spark assisted compression ignition (SACl) [13]. Previous experimental work in SI engines operating with homogenous charge at partial load suggests the suitability of this method for adjusting combustion phasing, providing a fast enough response for cycle-to-cycle control. Nevertheless, further research on spark assistance in new combustion modes is necessary for continuing its development with low reactivity fuels $[15,16]$.

Thus, the aim of this work is focused on the study of the integration of phasing cycle-to-cycle control by means of an ignition spark plug system in a $\mathrm{Cl}$ engine working in partially premixed charge (PPC) in order to overcome the lack of combustion stability in light load conditions when very low fuel reactivity is used. This engine has a high compression ratio and it is equipped with a common rail injection system that enables high-pressure injection and EGR and temperature control. Moreover, the experimental work was carried out using a low reactivity fuel such as gasoline. In addition the investigation was performed in an optical engine since it is a suitable tool for developing a basic combustion research combining two different sources of experimental information: in-cylinder pressure signal and optical combustion images.

In an attempt to improve the fundamental understanding of this combustion process, this paper is focused on describing and explaining the phenomenology of the gasoline partially premixed combustion compression ignition with spark assistance mode, and also on the understanding the role and the effects of the load on the performance of this combustion mode.

The outline of this paper is as follows: in a first short section, the experimental facilities and set up used to carry out this research are described. The subsequent section presents a detailed description of the methodology and tools explaining the methodology followed to obtain the raw results and also the post-processing codes to produce the final information for the analysis. In section 4, the phenomenology of the combustion process will be described and in section 5 the results of a study focused on evaluating the effect of the engine load will be discussed. Finally, the main conclusions of this research work have been summarized.

\section{Experimental setup}

This section presents a description of the experimental facility and the different devices and systems that were specifically adapted for the study of this combustion mode. All the experimental information has been obtained in a single cylinder optical engine [17] with a modified cylinder head, thus enabling the introduction of the spark plug in the combustion chamber.

\subsection{Experimental facilities}

\subsubsection{Engine description}

The optical engine used in the present study is a 4-valve, 0.545 liter displacement single cylinder engine with a cylinder head modified for studying this combustion mode. The engine is equipped with an elongated piston with a cylindrical bowl, which allows optical access to the combustion chamber through a sapphire window placed in its 
bottom. The bowl dimensions are $45 \times 18 \mathrm{~mm}$ (diameter $\mathrm{x}$ depth). Below the piston bowl, an elliptical UV mirror is placed on the cylinder axis. In front of the mirror a high speed camera is positioned to record images from the combustion chamber. The conventional diesel cylinder head has been modified to accommodate a spark plug. A standard NGK spark plug with an $0.8 \mathrm{~mm}$ gap is used along with an electronic control system. In the standard configuration, the tip protrudes $4.5 \mathrm{~mm}$ into the combustion chamber below the cylinder head plane and it is located $17 \mathrm{~mm}$ from the cylinder axis. It is operated at a constant nominal primary voltage of $14 \mathrm{~V}$ and primary current of $11 \mathrm{~A}$, achieving a secondary discharge peak of $25 \mathrm{KV}$. Figure 1 shows a sketch of the optical access in the single cylinder engine as well as the different elements that are included.

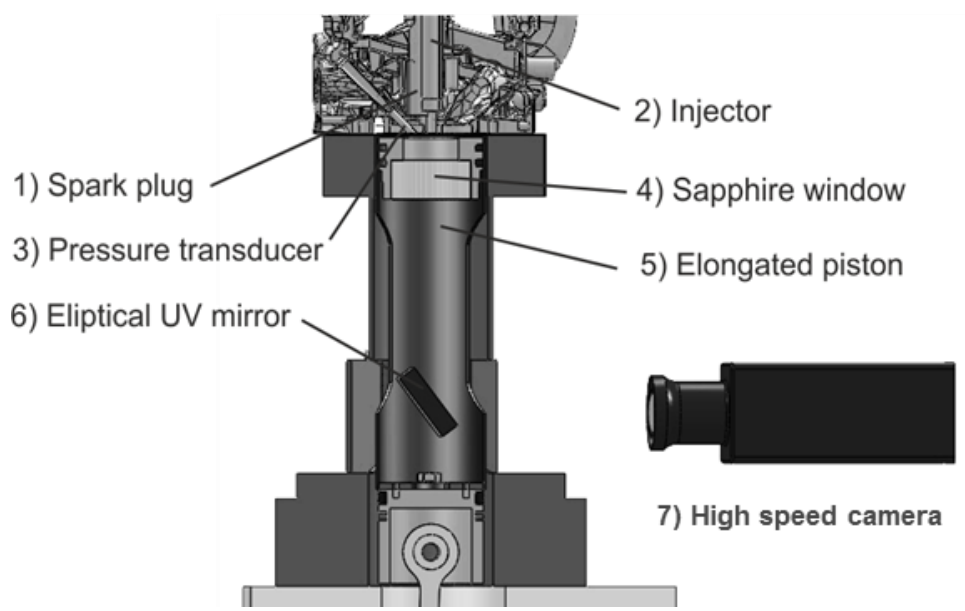

Figure 1: Sketch of the optical acces in the single cylinder engine with different elements. (1) Spark Plug, (2) injector nozzle, (3) pressure transducer, (4) sapphire window, (5) elongated piston, (6) elliptical UV mirror and (7) High speed camera.

The air supply has been modified to accommodate PPC combustion in the optical engine. A decreased oxygen concentration is needed and experimental tests must be performed under skip-fire mode in order to avoid excessive thermal stress in the windows. Therefore, the oxygen concentration variation is performed using synthetic EGR. Nitrogen gas is substituted for EGR, which greatly simplifies the system ensuring a controllable gas composition without an excessive time to adjust the facility. The concept is based on decreasing the $\mathrm{O}_{2}$ concentration at the inlet manifold by increasing the amount of $\mathrm{N}_{2}$ keeping the total intake mass flow rate constant (substitution EGR) [18]. With this system, thermodynamic conditions within the combustion chamber can be reproduced systematically. The compression ratio was adjusted to 14.7:1, representative of a typical PPC engine.

\subsubsection{Fuel and injection system}

The fuel properties were analyzed to characterize the most relevant properties of the gasoline used. Thermodynamic properties and energetic content were measured following ASTM standards and the results are summarized in Table 1.

\begin{tabular}{l|c}
\hline \multicolumn{1}{c|}{ Fuel } & Gasoline \\
\hline Density $\left[\mathrm{kg} / \mathrm{m}^{3}\right]\left(\mathrm{T}=15^{\circ} \mathrm{C}\right)$ & 722 \\
Viscosity $\left[\mathrm{mm}^{2} / \mathrm{s}\right]\left(\mathrm{T}=40^{\circ} \mathrm{C}\right)$ & 0.37 \\
RON $[-]$ & 98 \\
Lower heating value $[\mathrm{kJ} / \mathrm{kg}]$ & 44542 \\
\hline
\end{tabular}

Table 1: Characteristics of gasoline used in the study

Results show gasoline density, kinematic viscosity, octane number, and the lower heating value. Interestingly, if compared to diesel fuel, for which the injection system in use is designed, the main differences are the density and viscosity, with both showing a lower value for gasoline. Additionally, the lower heating value is slightly higher for gasoline than for diesel fuel. Viscosity shows the greatest difference between the two fuels and it is an important parameter in the operation of all systems related to the injection. For this research, an additive was used to control the viscosity of the gasoline and increase the service life of the high pressure pump and injector. 
The fuel injection system is based on an electronically controlled Bosch common rail system. The injector is a Bosch piezoelectric CRIP 3.3 model equipped with a seven-hole nozzle with $154^{\circ}$ included angle. The nozzle hole diameter is 97 microns and its flow capacity is $210 \mathrm{~cm}^{3} / 30 \mathrm{~s}$. The injection control system makes it possible to modify any parameter of the injection events such as the start of injection timing, injection duration and rail pressure. The injector is centered in the cylinder and vertically mounted in the modified cylinder head with a graduated metal circle that can be used to change the relative position between the spark plug and the injector by rotating the latter around its vertical axis. Figure 2 shows the relative position between the spark and the different sprays.

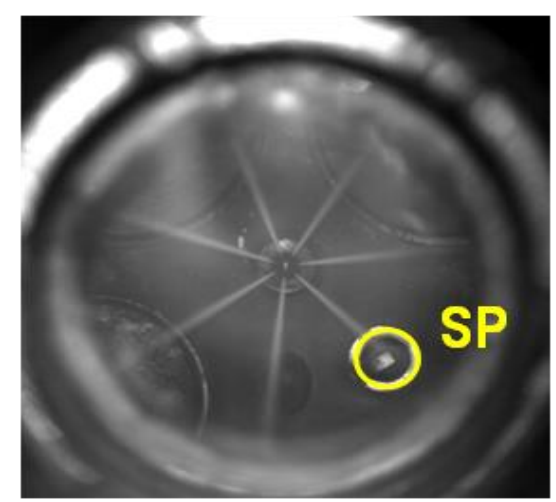

Figure 2: MIE scattering image showing the relative position between the spark plug and the different sprays.

\subsubsection{Optical devices}

The optical system includes a sapphire window which forms the bottom of the piston bowl and an elliptical mirror as shown in Figure 1. These allow reflecting the light that comes from the combustion process or illuminating the inside of the cylinder. In this study an external light source with an optical fiber and a collimator is used with a high speed camera to record images of the combustion process. These images are taken with a high speed Phantom V12 CMOS camera, equipped with a $100 \mathrm{~mm}$ focal length ZEISS lens. The camera has an image resolution of $512 \times 512$ pixels. This resolution, along with an acquisition frequency of $10000 \mathrm{fps}$, was used in order to capture the spark plug discharge and the combustion process events. The exposure time is 100 microseconds, which is the maximum time allowed by the camera at the selected acquisition frequency. This setup was designed to acquire as much light as possible from the first reactions in the chamber and from everything that happened around spark the plug. The images will saturate in those cases producing high luminosity combustion conditions.

Two optical techniques have been used in the development of this work [21]. The first is a MIE scattering technique (showed in Figure 2) for the visualization of the relative position between the sprays and the spark plug. This technique uses an external light source and long exposure time. The second technique is visualization of broadband natural luminosity without optical filters and without external illumination. For this technique, the camera settings have been adjusted to avoid sensor saturation. The discharge of the spark plug and the combustion process are the primary light sources.

\section{Methodology and tools}

This section describes the different methodologies and tools used for conducting the experiments. Also an explanation is given of how the main results are obtained from the tests and how these results were analyzed to explain the fundamentals and phenomenology of this combustion mode.

\subsection{Conditions of the study}

During the testing, some engine conditions were kept constant while other conditions were varied in a series of parametric sweeps. Constant parameters throughout the study included the engine speed (750 rpm), the engine water and oil temperature (both at $80^{\circ} \mathrm{C}$ ), the injection pressure $(600 \mathrm{bar})$ and the injection events, only one main injection was used. The experimental reference point for the parametric variations was defined as: an injected mass of $21 \mathrm{mg} / \mathrm{stk}$, a start of injection timing of 19 CAD before TDC, an intake oxygen concentration of $18 \%$, an 
air intake temperature of $35{ }^{\circ} \mathrm{C}$, an air intake pressure of 1.6 bar and a start of spark timing set at the end of injection. Table 2 presents the settings used in the experimental tests. The tests were conducted in skip-fire mode with only one injection performed every 30 cycles. This was done in order to avoid variations in the in-cylinder conditions due to cycle-to-cycle combustion dispersion and to reduce thermal stress on the windows. For each operating point, 10 combustion cycles were recorded.

\begin{tabular}{l|l|c}
\hline Parameter & Unit & Value \\
\hline Fixed: & & \\
Engine speed & {$[\mathrm{RPM}]$} & 750 \\
Water / Oil temperature & {$\left[{ }^{\circ} \mathrm{C}\right]$} & 80 \\
Injection pressure & {$[\mathrm{bar}]$} & 600 \\
Injection strategy & {$[-]$} & single injection \\
Variable: & & \\
Start of injection & {$[\mathrm{CAD}]$} & $19 \mathrm{bTDC}$ \\
Air intake temperature & {$\left[{ }^{\circ} \mathrm{C}\right]$} & 35 \\
Air intake pressure & {$[\mathrm{bar}]$} & 1.6 \\
Injected mass & {$[\mathrm{mg} / \mathrm{stk}]$} & 21 \\
Start of spark & {$[\mathrm{CAD}]$} & $10.8 \mathrm{bTDC}$ \\
Oxygen concentration & {$[\%]$} & $18 \%$ \\
\hline
\end{tabular}

Table 2: Main characteristics of experimental reference test

\subsection{Analysis of pressure signal}

The tool employed to perform the combustion analysis is the one-zone model CALMEC, which is fully described in [19]. This combustion diagnosis tool uses the measured in-cylinder pressure as its main input and other engine parameters as boundary conditions of the tests. Then, the first law of thermodynamics is applied between IVC and EVO, considering the chamber as an open system because of blow-by and fuel injection. The ideal gas equation of state is used to calculate the mean gas temperature in the chamber. Along with these two basic equations, several sub-models are used to calculate instantaneous volume and heat transfer [20], among others. The model main result is the Rate of Heat Release (ROHR). But the instantaneous evolution of other parameters like the Heat Release Law (HRL, defined as the integral of ROHR and normalized with respect to its maximum) can be calculated. Time resolution for these variables depends on the crank angle encoder configuration, which is 0.2 CAD in this research. Then, global information on each cycle can be obtained, such as Indicated Mean Effective Pressure (IMEP), Start of Combustion (SOC) and CA25. SOC is defined as the crank angle position where the beginning of the steep rise in ROHR due to combustion is detected. For a given cycle, CA25 is defined as the crank angle where the $25 \%$ of the total combustion energy has been released. Finally, the fuel energy conversion efficiency, $F_{E} C E$, is defined as the ratio between the total energy released in one cycle and total energy available in the fuel injected. Where the energy released in one cycle is the integral of the ROHR calculated between IVC and EVO:

$$
F_{E} C E=\frac{100}{m_{f} * H v} \cdot \int_{I V C}^{E V O} \operatorname{RoHR}(\alpha) d \alpha
$$

Since it was not possible to calculate the combustion efficiency from emissions measurements for this work, the $F_{E} C E$ was used as an estimate of the combustion efficiency.

\subsection{Images and post-processing}

In order to improve the quality of the combustion analysis, time resolved parameters were calculated for every image in each sequence following a well-defined methodology. First, segmentation was performed for every image by calculating a threshold value, which is equal to the minimum digital level in the image plus $15 \%$ of the difference between the maximum and the minimum. This percentage was chosen, based on previous experience, as a compromise to eliminate light reflected off the liquid spray and the chamber walls without losing much information from the combustion event. After segmentation, the digital levels of all pixels containing the combustion radiation (those above the threshold) are accumulated in a single parameter named Icummul (accumulated light intensity) and the flame area is defined as the summation of the number of pixels belonging to 
the flame (above the threshold). Additionally, as shown in Figure 3, the integrated luminosity (IL) is defined as the integral of the instantaneous I cummul $_{\text {and }} \mathrm{LD}_{25}$ as the time between the start of injection and the time where $25 \%$ of the integrated luminosity is delivered.

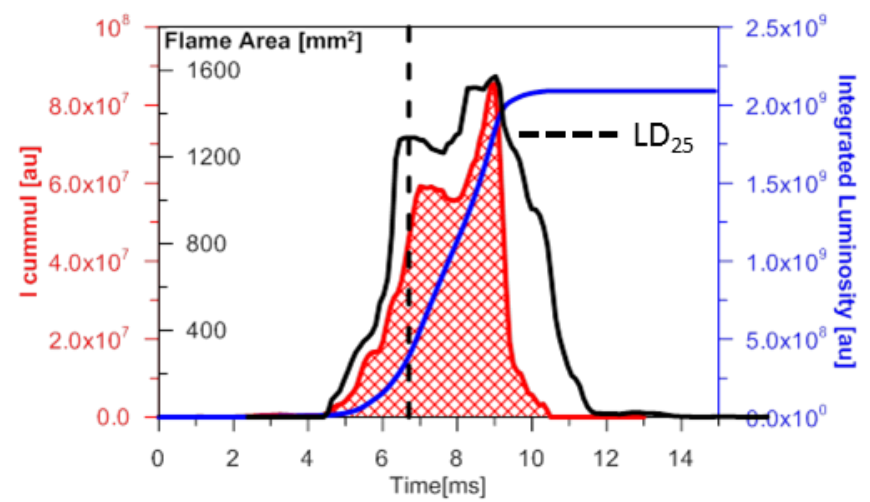

Figure 3.Temporal evolution of the accumulated light intensity $\left(I_{\text {cummul }}\right)$. The integrated luminosity, IL, is defined as the area under the $I_{\text {cummul }}$ trace. The $\mathrm{LD}_{25}$ is defined as the time from Sol to the time where $25 \%$ of the IL is obtained.

\section{Influence of spark assistance on gasoline partially premixed combustion}

This section describes the gasoline partially premixed compression ignition mode with spark assistance. Images of natural luminosity of combustion have been analyzed and combined with several relevant parameters obtained from the in-cylinder pressure signal. These derived parameters are very useful in order to provide a better understanding of the different phenomena observed during the combustion process. The following description of the combustion process is based on the reference case as defined in Table 2.
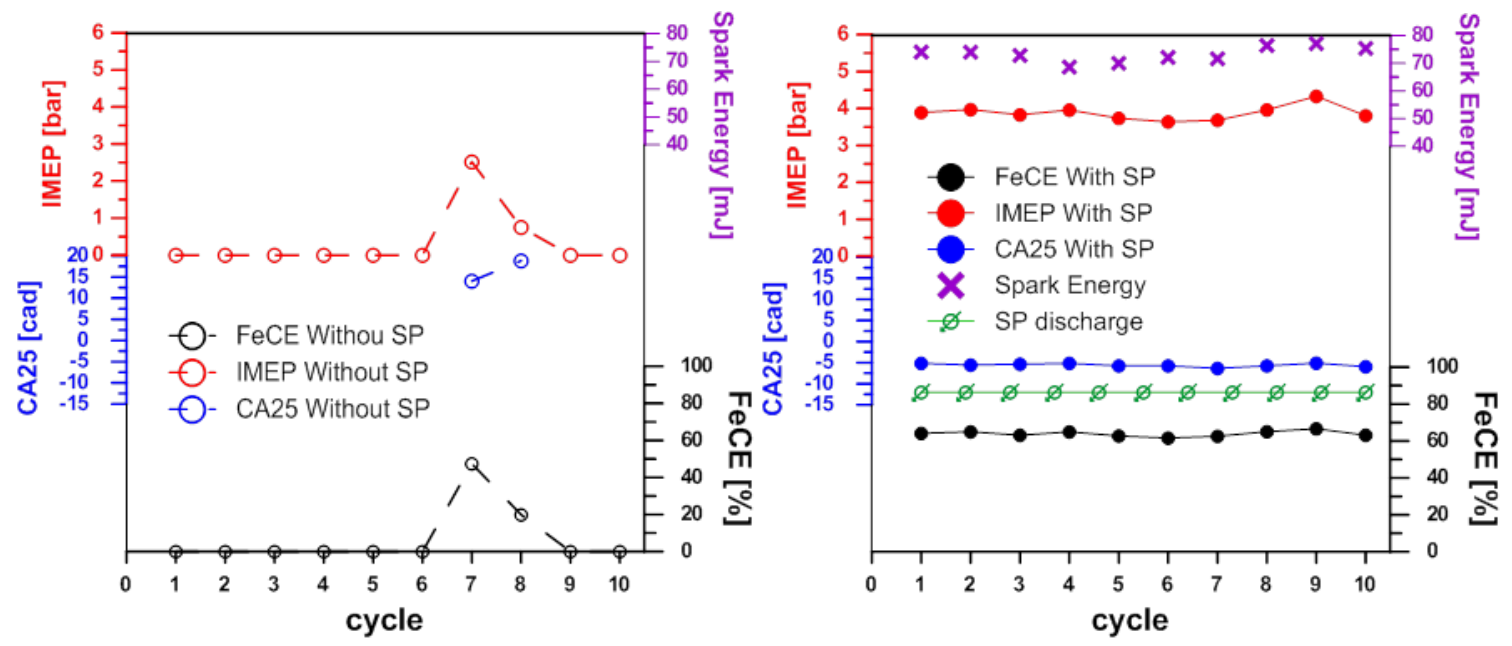

Figure 4. Left: IMEP, $\mathrm{CA}_{25}, \mathrm{~F}_{\mathrm{E}} \mathrm{CE}$ versus the repetition number for 10 repetition tests of partially premixed with auto-ignition combustion without spark assistance. Right: IMEP, $\mathrm{CA}_{25}, \mathrm{~F}_{\mathrm{E}} \mathrm{CE}$ versus the repetition number for 10 repetition tests of partially premixed combustion with spark assistance.

The effect of spark assistance for inducing the onset of combustion is shown in Figure 4, where the $\mathrm{CA}_{25}$, the IMEP and the fuel energy conversion efficiency $\left(F_{E} C E\right)$ have been plotted against the cycle number for ten consecutive cycles. Two interesting results can be observed in this figure by comparing the results without (right) and with (left) spark assistance. Without the spark assistance, only two of the ten cycles produce any measurable IMEP confirming the well-known lack of combustion stability at light load conditions. By contrast, forcing the onset of combustion with the spark assistance improves the combustion stability since all the consecutive cycles not only produce positive IMEP values, but also higher IMEP levels than what was obtained without the spark assistance. The higher fuel energy conversion efficiency ( $\left.F_{E} C E\right)$ confirms the benefits of assisting the onset of combustion with a spark. 
The spark assistance also seems to provide control over the combustion phasing. The crank angle where the start of the spark discharge occurs is marked on the right plot in Figure 4. This figure shows how the $\mathrm{CA}_{25}$ is close to the time of the spark discharge and is also close to TDC compared with the case without spark assistance. Figure 5 presents a comparison of the results derived from the in-cylinder pressure diagnostics to those derived from optical images.
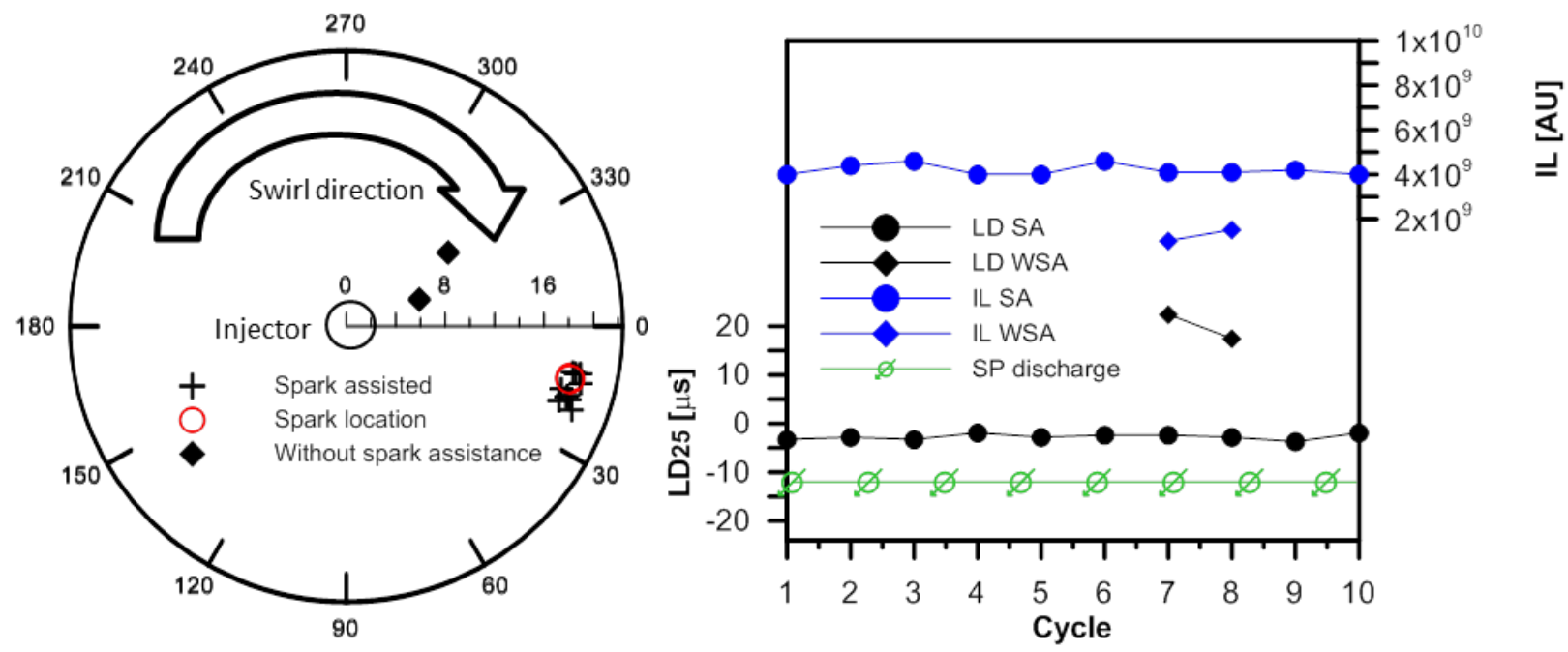

Figure 5. Left: Location of the first luminosity spot detected plotted in polar coordinates for cases with and without spark assistance (when spark assistance is used the first spot luminosity is considered after the end of spark discharge); the red circle shows the location of the spark plug. Right: $\mathrm{LD}_{25}$ and ID versus the cycle number for a 10 cycle test on a partially premixed combustion with and without spark assistance.

A sketch of the piston bowl showing the location of the first luminosity spot is shown in Figure 5 (left), plotted in polar coordinates. Considering the cases without spark assistance, the two working cycles present their first luminosity spots without any specific location; however, for the cases with spark assistance the first luminosity spots are located downstream of the spark plug in the swirl direction. It is worth noting how, using the spark assistance, the first spot luminosity is observed just after the end of the spark discharge and therefore, it indicates that the spark is governing spatially the onset of the combustion process.

The right part of Figure 5 shows the luminosity delay $\left(\mathrm{LD}_{25}\right)$, the integrated luminosity (IL) and the crank angle when the start of the spark discharge occurs versus the cycle number for 10 consecutive cycles with and without spark assistance. For the cases with spark assistance, the $\mathrm{LD}_{25}$ is stable and (compare to CAD for CA25 in Figure 4), but in contrast, the cases without spark assistance show longer and less stable $L D_{25}$ times. Thus, results using the luminosity delay are consistent with the $\mathrm{CA}_{25}$ results and, consequently, the spark timing is governing temporally the start of the combustion process. Similarly, the IL results are also consistent with the IMEP measurements and the $\mathrm{F}_{\mathrm{E}} \mathrm{CE}$ results. Under these operating conditions, when the spark assists the combustion process, it is much more stable and provides higher IL and IMEP levels, together with higher fuel energy conversion efficiency.

\subsection{Description of the combustion event}

After confirming the potential of the spark assistance to affect the PPC combustion mode, this section includes a description of the fundamental phenomena involved in this advanced combustion concept. Figure 6 shows the temporal evolution of broadband-natural luminosity images inside the combustion chamber for a representative cycle of the reference case. The images are referenced with respect to TDC and the crank angle position is shown in the bottom-left corner of each image. White-radial lines on the images correspond to the approximate locations of the sprays, while the red circle shows the location of the spark plug. 

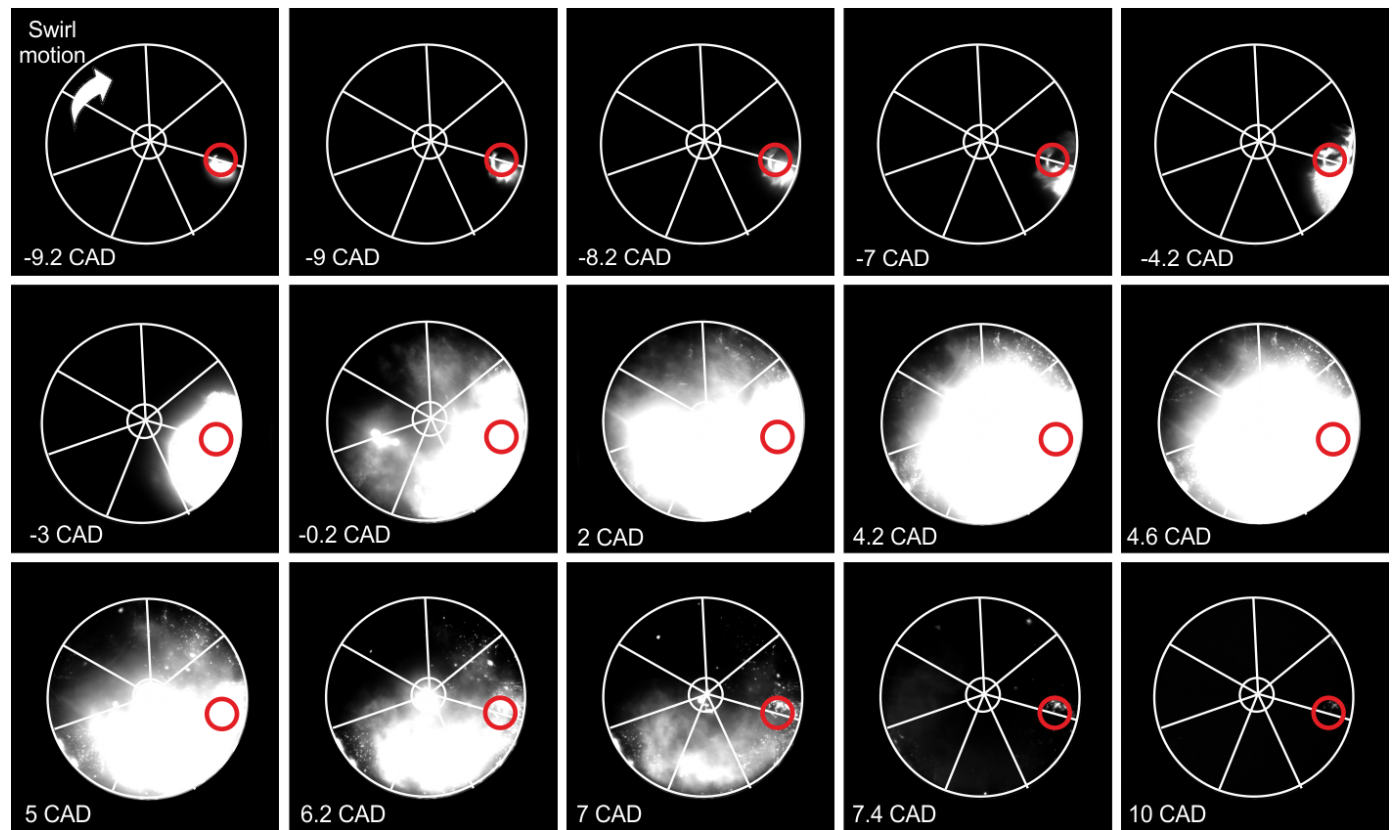

Figure 6. Temporal evolution of broadband-natural luminosity images inside the combustion chamber. Images are referenced with respect to TDC. White-radial lines on the images correspond to the approximate location of the sprays while red circle represents the location of the spark plug. Crank angle position is shown in the bottom-left corner of each image.

After the spark discharge, at -9.2 CAD, a high luminosity area is observed around it. This active site shifts towards the combustion chamber wall following the spray path. At -7 CAD, the luminous area begins to grow and is surrounded by a much larger zone with higher intensity. The reaction zone growth progresses with a slight increase in its size, following the swirl direction and close to the spray ignited by the spark plug. This stage finishes between -0.2 CAD and 2 CAD (exactly in 0.6 CAD) after which a second increase in the luminous area is observed. During this phase, the luminous area progresses towards the rest of the combustion chamber with a relatively higher intensity. However, it is interesting to note that the region of the chamber located on the opposite side from the spark plug location does not show significant luminosity. Therefore, this is a portion of injected mass which is not completely burnt, explaining the moderate fuel energy conversion efficiency previously observed for this combustion concept. Finally, after $7 \mathrm{CAD}$, the luminous zone starts to decrease in size, which leads to the extinction of the reaction zone.

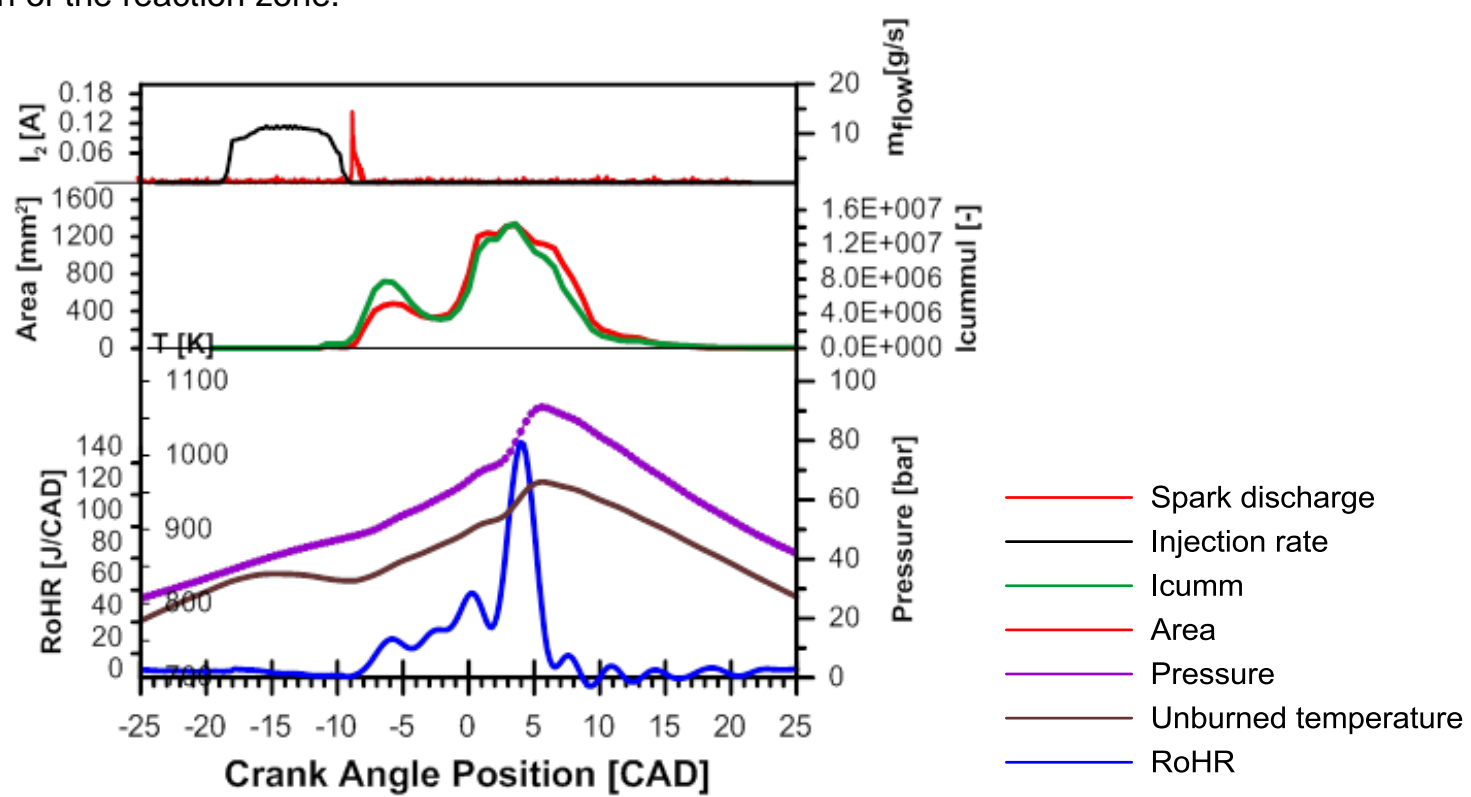

Figure 7: Crank angle evolution of different variables. From the top to bottom: injection rate and spark discharge intensity, image processed variables (cumulative intensity and flame area) and in-cylinder pressure variables (unburned temperature, pressure, and rate of heat released) 
The previous qualitative sequence of images can be analyzed in terms of quantitative variables derived from incylinder pressure and image processing as shown in Figure 7. The evolution of the flame area and accumulated light intensity (Icumm) are in agreement with the images shown in Figure 6: spark discharge occurs at -9.2 CAD, and no large increase in flame area occurs until approximately -7 CAD. During that interval, only the spark and the first moments of the combustion event are generating radiation. From $-7 \mathrm{CAD}$ to approximately $0.6 \mathrm{CAD}$, the phase of the compact radiation area evolution occurs. From 0.6 CAD onwards, a second combustion period occurs with the corresponding increase in both parameters; flame area and accumulated light intensity. These periods are observed to be approximately coincident with those observed in the pressure-derived parameters such as heat release rate, unburned temperature and pressure. Thus, once the combustion process is started by the spark plug, a first phase with an almost linear, sustained heat release occurs until 0.6 CAD, after which a second period with a noticeable peak in heat released occurs. Differences between the first and second phases in heat release rate indicate that the second one is faster than the first one.

The analysis of these quantitative parameters makes it possible to define the main characteristics of the combustion process. After the spark discharge, a growth of an early flame kernel takes place with negligible heat release ( -9.2 to $-7 \mathrm{CAD})$. The kernel phase is followed by a flame front propagation under partially premixed conditions (-7 to $0.6 \mathrm{CAD}$ ). Energy released by the premixed reaction causes an increase in temperature and pressure in the combustion chamber, leading to the auto-ignition of the rest of the mixture (0.6 to $7 \mathrm{CAD})$. The main difference between the auto-ignition and the premixed combustion phases is the propagation rate and, as a consequence, the maximum rate of heat release. Moreover, it can be seen that the reaction is not uniform across the combustion chamber. While the premixed combustion takes place around the spark plug, the auto-ignition phenomenon extends across almost the whole field of view.

\section{Effect of injected mass on combustion mode}

The previous sections pointed out the potential of spark assistance for improving the combustion performance of the partially premixed combustion concept, including also a fundamental characterization of the resulting combustion process. For the operating condition described in Table 2, the spark plug is, without any doubt, the main ignition promoter controlling spatially and temporally the start of combustion. In this section, the effect of varying the total fuel mass is investigated by operating the engine with three different levels of injected fuel mass $(15,18$ and $23 \mathrm{mg} / \mathrm{stk})$, while keeping the other engine settings constant. Figure 8 shows the main in-cylinder pressure related parameters (IMEP, $\mathrm{CA}_{25}$ and $\mathrm{F}_{\mathrm{E}} \mathrm{CE}$ ) for the 15 and $23 \mathrm{mg}$ cases against the cycle number for 10 consecutive cycles with and without spark assistance.
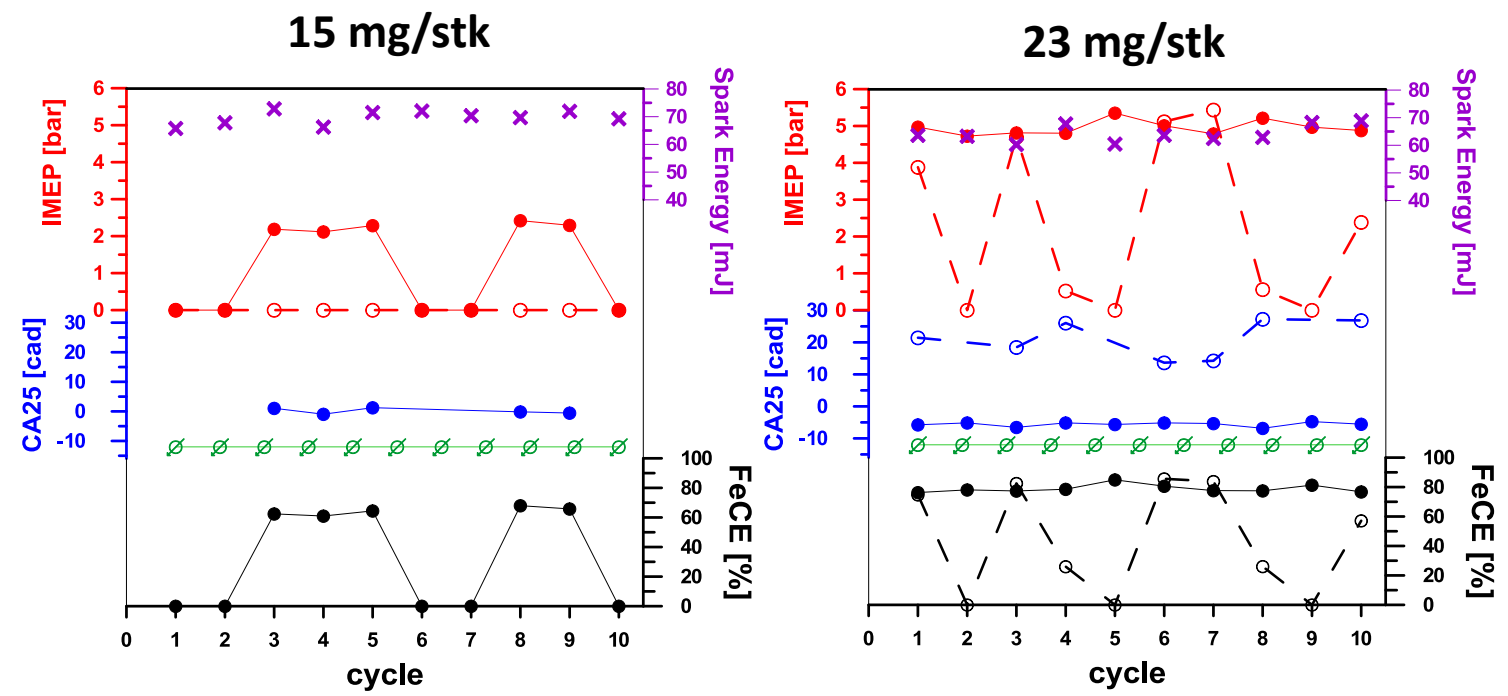

Figure 8: IMEP, $\mathrm{CA}_{25}, \mathrm{~F}_{\mathrm{E}} \mathrm{CE}$, spark energy and spark timing for $15 \mathrm{mg}$ injected mass (left) and $23 \mathrm{mg}$ injected mass (right) versus the cycle number for a 10 cycle test of PPC comparing cases with and without spark assistance.

Considering the $15 \mathrm{mg}$ injected mass cases shown in Figure 8 (left), none of the cycles without spark assistance produces positive IMEP levels, so combustion is not progressing. This result is in agreement with the literature, 
[22] showing an area in the IMEP versus octane number map in which low reactivity fuels, with ON greater than 90, do not auto-ignite under thermodynamic conditions similar than those used in this study. Even after introducing the spark assistance, only five of the ten cycles produce positive IMEP levels and therefore operating under these conditions with this injected fuel mass could be considered as a threshold for the combustion concept. Figure 8 (right) shows the results for the $23 \mathrm{mg}$ injected fuel mass cases. As in the reference case discussed in previous sections, the spark assistance provides both higher stability in terms of a higher number of working cycles (positive IMEP), as well as higher IMEP levels and higher fuel energy conversion efficiencies. Additionally, it is evident how the spark controls the combustion phasing, since the $\mathrm{CA}_{25}$ is close to crank angle when spark discharge starts and therefore, it is also close to TDC. By contrast, for the cycles without spark assistance, the $\mathrm{CA}_{25}$ is shifted later in the expansion stroke. Thus, an increase in the injected fuel mass seems to have a positive effect on the assistance of the spark for both combustion stability and cycle to cycle control.

The following analysis is focused on the evaluation of the effects of injected fuel mass on the different phases of the combustion process. Figure 10 presents a comparison of different parameters extracted from the in-cylinder pressure and visualization images, while figure 9 shows a temporal evolution of the broadband-natural luminosity images inside the combustion chamber for the $15 \mathrm{mg}$ and $23 \mathrm{mg}$ injected fuel mass cases. The main combustion characteristics are similar to those described for the reference case. The initial onset of the combustion process is started by the spark plug discharge, then a slow development of visible flame occurs during the first combustion stage related to the progression of a flame front. This is followed by a subsequent acceleration of the combustion process with much higher light intensity in the second combustion stage and finally an extinction of the combustion process. Thus, the only differences in the combustion process caused by the total injected mass are mainly related with the duration and intensity of the different combustion phases.
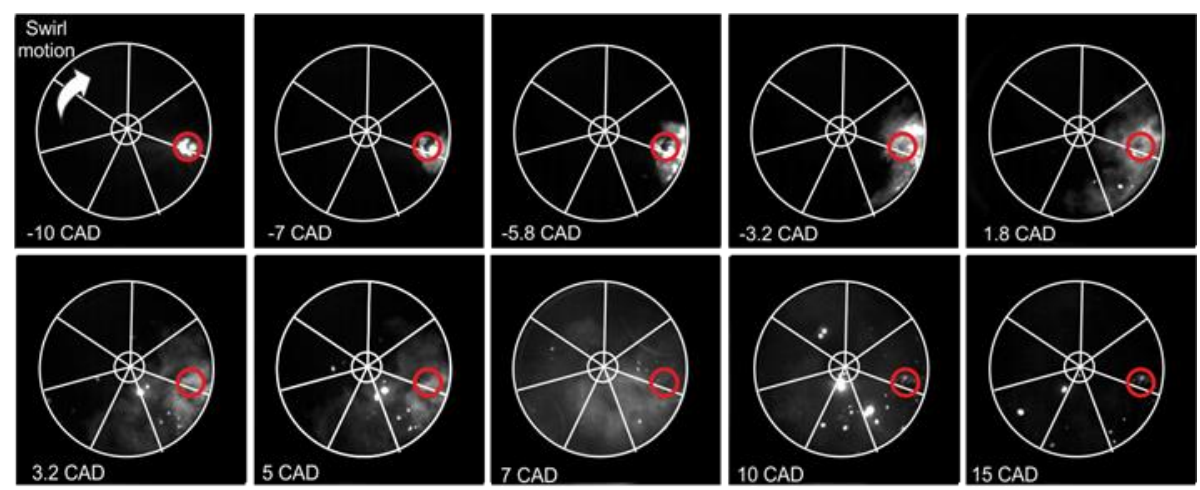

Image sequence from injected mass of $15 \mathrm{mg} / \mathrm{stk}$
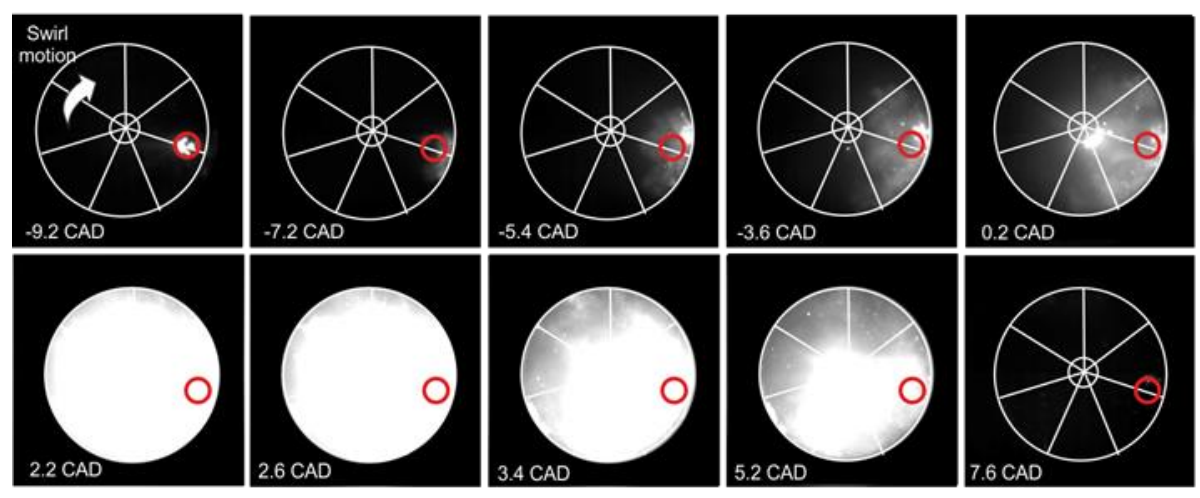

Image sequence from injected mass of $23 \mathrm{mg} / \mathrm{stk}$

Figure 9: Temporal evolution of broadband-natural luminosity images inside the combustion chamber comparing 15 and $23 \mathrm{mg} / \mathrm{stk}$ injected masses results. Figures are referenced with respect to TDC. White-radial lines on the images correspond to the approximate location of the sprays while red circle represents the location of the spark plug. Crank angle position is shown in the bottom-left corner of each image.

Comparing the duration of the first phase flame front progression, Figures 9 and 10 show how the case with lower injected fuel mass needs a longer times to develop. The ROHR and the flame images show that it is necessary to 
spend almost double the time to complete this stage of the combustion process for the lower injected fuel mass (15 CAD) compared to the case with the higher injected fuel mass (8 CAD). Consistent with the slower and weaker combustion process, the case with the lower injected fuel mass produces a lower total energy release. This result is observed in the ROHR profile and also by the lower accumulated light intensity. For the lowest injected fuel mass, the second phase of combustion (auto-ignition stage) is much less vigorous. Nevertheless, both cases show a similar durations before combustion extinction (around 5 CAD). However, the intensity of the combustion process is different.

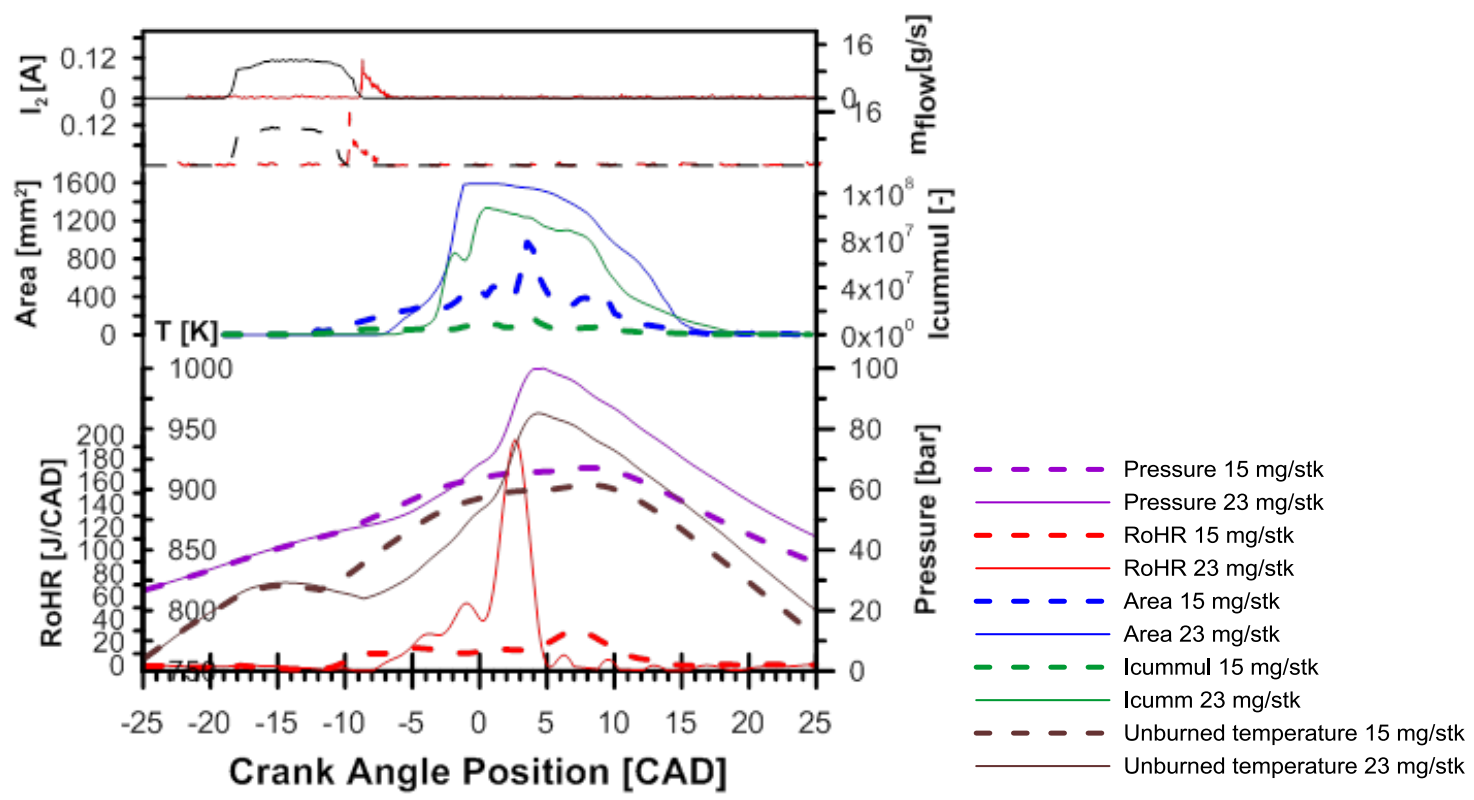

Figure 10: Crank angle evolution of different variables comparing 15 and $23 \mathrm{mg} / \mathrm{stk}$ injected mass. From the top to bottom: injection rate and spark discharge intensity, image processed variables (cumulative intensity and flame area) and in-cylinder pressure variables (unburned temperature, pressure, and rate of heat released).

Taking into account the thermodynamic conditions at the onset of both phases, the case with higher injected fuel mass should have worse conditions to promote ignition and combustion. Figure 10 shows lower unburned temperature and pressure at the start of the flame front propagation phase, and similar unburned temperature at the start of the auto-ignition combustion phase for the higher fuel mass case. However, the accumulated light intensity and the ROHR are clearly higher for this case. A possible explanation for this behavior is related to the richer equivalence ratio distribution inside the chamber due to the higher fuel mass is injected. This would indicate that the stratified premixed combustion has more capability to progress properly for the higher injected mass case. Since the mixing time available between the end of injection and the start of the auto-ignition stage is quite enough in both cases to attain well-premixed conditions (of course not fully homogeneous) then, the reactivity of the mixture is related to the average equivalence ratio in each case. For the higher injected fuel mass case the average equivalence ratio is 0.4 , which is more reactive than the 0.28 average equivalence ratio attained in the lowest fuel mass case. The higher equivalence ratio has a stronger effect on the auto-ignition than the moderate differences observed in the thermodynamic conditions, explaining the behavior shown by the ROHR and images. 


\section{Conclusions}

Direct visualization analysis of natural radiation has been combined with the analysis of parameters derived from in-cylinder pressure to show the usefulness of the Partially Premixed Spark Assisted Compression Ignition mode using gasoline with high octane number at light loads. Under these operating conditions, it was demonstrated that spark assistance is capable of providing temporal and spatial control over the combustion process by initiating a premixed flame that consumes a part of the charge and promotes autoignition in the remaining portion of the charge. Furthermore, spark assistance demonstrates the capability to enhance cycle to cycle repeatability for the highly premixed compression ignition modes under light load conditions.

A detailed description of the phenomena involved in the combustion process generated by this concept is also provided. The following stages have been identified: The process starts with the spark discharge, which produces a flame kernel around the spark plug that later evolves to a premixed flame front. This premixed flame compresses and heats the unburned mixture and progresses into an auto-ignition combustion mode, where the rest of the charge is burnt producing higher light intensity. Finally an extinction of the combustion process is observed at the end of the auto-ignition stage.

Finally, the effect of injected fuel mass on the combustion mode has been evaluated. The description of the characteristics of the combustion process was found to be similar for the different fueling quantities. Additionally, results confirm how an increase in the injected fuel mass has a positive effect on the performance of the partially premixed spark assisted combustion concept since an improvement was found in both combustion stability and cycle to cycle control. When the injected fuel mass is increased, the intensity of each phase of combustion is also increased and, by contrast, the duration is decreased. This behavior is explained due to a higher reactivity induced by a richer mixture, which was proven to be more relevant for promoting the auto-ignition of the mixture than the thermodynamic conditions. In spite of this effect of fueling quantity, spark assistance was found to be capable of extending the limits of the gasoline $\mathrm{Cl}$ combustion mode to lower fueling levels than was possible without the spark assistance.

\section{Acknowledgments}

The authors would like to thank General Motors for supporting this research.

\section{References}

1. Yanagihara, H., Sato, Y. and Minuta, J., "A simultaneous reduction in NOx and soot in diesel engines under a new combustion system (Uniform Bulky Combustion System -UNIBUS)", 17th International Vienna Motor Symposium, pp 303-314, 1996.

2. Kimura, S., Aoki, O., Ogawa, H., Muranaka, S. et al., "New Combustion Concept for Ultra-Clean and HighEfficiency Small DI Diesel Engines," SAE Technical Paper 1999-01-3681, 1999.

3. Akagawa, H., Miyamoto, T., Harada, A., Sasaki, S. et al., "Approaches to Solve Problems of the Premixed Lean Diesel Combustion," SAE Technical Paper 1999-01-0183, 1999.

4. Kimura S., Aoki S., Kitahara Y., Aiyoshizawa E. Ultra-clean combustion technology combining a lowtemperature and premixed combustion concept for meeting future emission standards. SAE International, SAE 2001-01-0200, 2001.

5. Mingfa Yao, Zhaolei Zheng, Haifeng Liu, "Progress and recent trends in homogeneous charge compression ignition $(\mathrm{HCCl})$ engines". Progress in Energy and Combustion Science, Volume 35, Issue 5, October 2009, Pages 398-437

6. Hanson, R. M., Kokjohn, S. L., Splitter, D. A, and Reitz, R. D. "An experimental Investigation of Fuel Reativity Controlled PCCI Combustion in a Heavy-Duty Engine" SAE international journal of engines, 2010, 3(1) 700 716. 
7. B. Keeler and P. J. Shayler, "Constraints on Fuel Injection and EGR Strategies for Diesel PCCI-Type Combustion". SAE 2008-01-1327.

8. Yang, J., Culp,T., and Kenney, T. Development of a gasoline engine system using HCCl technology- The concept and the test results. SAE paper 2002-1-2832

9. Kalghatgi, G.T., Risberg, P., and Ångström, H.-E., "Advantages of Fuels with High Resistance to Auto-Ignition in Late-Injection, Low-Temperature, Compression Ignition Combustion," SAE Technical Paper 2006-01-3385, 2006.

10. Kalghatgi, G.T., Risberg, P., and Ångström, H.-E., "Partially Pre-Mixed Auto-Ignition of Gasoline to Attain Low Smoke and Low NOx at High Load in a Compression Ignition Engine and Comparison with a Diesel Fuel," SAE Technical Paper 2007-01-0006, 2007.

11. Hildingsson, L., Kalghatgi, G., Tait, N., Johansson, B. et al., "Fuel Octane Effects in the Partially Premixed Combustion Regime in Compression Ignition Engines," SAE Technical Paper 2009-01-2648, 2009.

12. Sjoberg, $\mathrm{M}$ and Dec, J.E. "Smoothing $\mathrm{HCCl}$ Heat-Release using partial fuel stratification with two-stage ignition fuels". SAE 2006-01-0629, 2006.

13. H. Persson, A. Rémon, A. Hultqvist, B. Johansson, "Investigation of the early flame development in spark assisted $\mathrm{HCCl}$ Combustion Using high speed chemiluminescence Imaging". SAE 2007-01-0212

14. H. Persson, A. Rémon, B. Johansson, "The effect of swirl on spark assisted compression ignition (SACI)" JSAE20077167, SAE 2007-01-1856

15. Wang, Z., Shuai, S.J., and Wang, J.-X., G-H Tian, Xinliang, Q-J Ma "Study of the effect of spark ignition on gasoline $\mathrm{HCCl}$ combustion". Proceedings of the Institution of mechanical Engineers, Part D: Journal of Automobile Engineering. DOI:10.1243/09544070JAUTO151

16. Vinod K. Natajaran, Volker Sick, David L. Reuus and Gerald Silvas, "effect of spark-ignition on combustion periods during spark assisted compression ignition". Combustion Sci. and Tech, 181:1187-1206,2009

17. Benajes J, López JJ, Novella R, Garcia A: "Advanced Methodology for Improving Testing Efficiency in a Single-Cylinder Research Diesel Engine"; Experimental Techniques 32:41-47, 2008.

18. J. Benajes, R. Novella, A. Garcia, V. Domenech, "An investigation on mixing and autoignition using diesel and gasoline in a direct injection compression ignition engine operating in PCCl combustion conditions". SAE Int. J. Engines August 2011 4:2590-2602; doi:10.42712011-37-0008

19. Lapuerta M, Armas $O$ and Hernández JJ: "Diagnostic of D.I. Diesel Combustion from In-Cylinder Pressure Signal by Estimation of Mean Thermodynamic Properties of the Gas", Applied Thermal Engineering. Vol 19 № 5 pp 513-529, 1999.

20. Payri F, Molina S, Martín J and Armas O: "Influence of measurement errors and estimated parameters on combustion diagnosis", Applied Thermal Engineering Vol 26 № 2-3 pp 226-236, 2006.

21. J.V. Pastor, J.M. Garcia-Oliver, J.M. Pastor, J.G. Ramirez-Hernandez, "Ignition and combustion development for high speed direct injection diesel engines under low temperature cold start conditions". Fuel (2011), doi:10.1016/j.fuel.2011.01.008

22. B Johansson, "Path to High Efficiency Gasoline Engine". DEER 2010 Lund University.

\section{Glossary}


$\mathrm{XO}_{2}$ : Oxygen concentration

EGR: Exhaust Gas Recirculation

Eol: End of Injection

HCCl: Homogeneous Charge Compression Ignition

IMEP: Indicated Mean Effective Pressure

LTC: Low Temperature Combustion

NOx: Nitrogen oxides

PCCl: Premixed Charge Compression Ignition

ROHR: Rate of Heat Release

Sol: Start of Injection

SoS : Start of spark

TDC: Top Dead Center 